\title{
Association of Interleukin-10 gene promoter polymorphisms in Saudi patients with Vitiligo
}

\author{
Abdullah Abanmi, Fahad Al Harthi, Abdulrahman Zouman, Aida Kudwah, Mohammed Al Jamal, \\ Misbahul Arfin and Mohammad Tariq* \\ Department of Dermatology, Research Center, Armed Forces Hospital, Riyadh, Saudi Arabia
}

\begin{abstract}
The promoter region of human Interleukin -10 gene is highly polymorphic and has been associated with numerous autoimmune diseases. Recent studies have linked vitiligo with defective autoimmune system. This study is aimed to explore a possible association between IL-10 gene polymorphism and vitiligo in Saudi population. This case control study consisted of 184 Saudi subjects including 83 vitiligo patients ( 40 males, 43 females mean age $27.85 \pm 12.43$ years) and 101 matched controls. Genomic DNA was extracted from the blood samples of healthy controls and Vitiligo patients visiting out patient clinic of Department of Dermatology, Riyadh Armed Forces Hospital, using QIA amp ${ }^{R}$ DNA mini kit (Qiagen CA, USA). Interleukin-10 gene was amplified by polymerase chain reaction (PCR) using Arms primers to detect any polymorphism involved at positions $-592,-819$ and -1082 .

The frequencies of GG genotype at -1082 , and CC genotype at positions -592 and 819 were significantly higher in vitiligo patients compared to healthy subjects suggesting that GG and CC genotypes might be susceptible to vitiligo in Saudis. On the other hand genotypes $-1082 \mathrm{GA},-819 \mathrm{CT}$, and $-592 \mathrm{CA}$ of IL-10 were more prevalent in healthy controls suggesting protective effects of GA, CT and CA genotypes against vitiligo. This study indicates that the IL-10 gene may play a significant role in the etiology of vitiligo among Saudis.
\end{abstract}

Keywords: Interleukin-10, polymorphism, vitiligo, Saudis

\section{Introduction}

Vitiligo is a puzzling disorder characterized by the appearance of white patches resulting from the loss of functional melanocytes and melanin from the skin. This common disorder involves $1-4 \%$ of the world population. Several theories concerning the etiopathology of vitiligo have been suggested including autoimmunity, inherent defects in melanocyte biochemistry and neuronal dysfunction [23]. In fact, familial aggregation of vitiligo is quite common with up to $20 \%$ of vitiligo patients having at least one first degree relative affected with the disease, clearly indicating genetic basis of

*Corresponding author: Prof. Mohammad Tariq PhD, FRC Path, FRSC, Sr. Consultant \& Director of Research Center, Armed Forces Hospital, P.O. Box 7897 (W 912), Riyadh 11159, Saudi Arabia. Tel.: +9661 4777714 ext. 25602; Fax: +966 14777714 ext. 23066; E-mail: rkhres@yahoo.com. vitiligo susceptibility $[1,47]$. It has been proposed that genes at different loci may contribute to the pathogenesis of vitiligo [1,15,38,43,49,56].

Recently, significant changes in cytokines levels were reported in vitiligo affected skin compared with pre-lesional, non-lesional and healthy skin suggesting that the cytokine production in epidermal microenvironment may play a role in pathogenesis of vitiligo [2, 58]. Individual differences in the inheritance of polymorphic gene lead to variation in their immune responses $[3,24]$ clearly indicating that cytokine gene polymorphism may reflect or control severity and progression of various diseases [25]. Several studies have addressed the role of peripheral blood and lesional cytokine expression in patients with vitiligo $[58,63]$. These authors suggested a role for epidermal cytokine imbalance in the pathogenesis of vitiligo.

Interleukin-10 (IL-10) is a cytokine functionally characterized by anti-inflammatory effects [39]. IL- 
10 is produced by a wide variety of cell types, including Th-cells, monocytes, macrophages, mast cells, eosinophils and keratinocytes [33]. This cytokine is a global suppressor of immune responses as well as an immunoregulator of the Th-cell response [34]. Moreover, a direct ability of IL-10 to down-regulate TNF $\alpha$, IL-1, IL- 8 and interferon- $\gamma$, production makes it one of the most important immunoregulator as well as a mediator of inflammatory process $[44,50,51]$. IL-10 is also a potent up-regulator of B-cell production and differentiation [18,59].

IL-10 gene maps to the junction of 1q31-q32 [27] and exhibits substantial polymorphism in the promoter region which appears to correlate with variations in transcription [14,61]. Various single nucleotide polymorphisms (SNPs) have also been identified in the promoter region of IL-10 gene, three of which $(-1082 \mathrm{G} / \mathrm{A}$, $-819 \mathrm{C} / \mathrm{T},-592 \mathrm{C} / \mathrm{A}$ ) have been found to be associated with a number of diseases [7,9,17,20,30,35,36,42,54, 55,57,64]. Recently Grimes et al. [45] suggested that IL-10, IFN- $\gamma$ and TNF- $\alpha$ may play a role in the pathogenesis of vitiligo and a statistically significant increase in the expression of these cytokines was observed in the lesional and paralesional skin of vitiligo patients as compared to controls.

Therefore, in this study it was aimed to investigate the association between genotype and allele frequencies of IL-10 gene especially in promoter region at $-1082,-819$ and -592 loci and vitiligo in Saudi patients.

\section{Results}

Eighty three Saudi vitiligo patients (40 male, 43 female, aged 6 to 79 , mean age $27.85 \pm 12.43$ years) and 101 healthy matched controls (71 males and 30 females) from same population were genotyped for three polymorphisms of IL-10 gene. Results of analysis of single nucleotide polymorphism (SNP) for IL-10 G(-1082)A, IL-10 C(-592)A, IL-10 C(-819)T, and corresponding genotypes using ARMS-PCR method are summarized in Tables 1-3.

The frequency of $-1082 \mathrm{GG}$ genotype was found to be significantly higher $(P=0.05)$ in vitiligo patients $(18.07 \%)$ as compared to controls subjects $(8.91 \%)$. On the contrary, the frequency of heterozygous genotype GA was significantly lower $(P=0.04)$ in patients $(60.24 \%)$ as compared to control subjects $(73.26 \%)$. No significant difference in the frequency of homozygous AA genotype was observed in patients $(21.68 \%)$ and controls (17.82\%). Genotype -1082GG seems to be susceptible to vitiligo $(\mathrm{RR}=2.25, \mathrm{EF}=0.34)$ while genotype $\mathrm{GA}$ is resistant to vitiligo $(\mathrm{RR}=0.55, \mathrm{PF}=$ 0.24 , Table 1).

The frequency of -819 CC genotype was significantly higher $(P=0.02)$ in the vitiligo patients $(56.62 \%)$ compared to controls $(39.60 \%)$ while CT showed a reverse pattern with lower frequency $(31.32 \%)$ in vitiligo patients as compared to $50.49 \%$ in controls $(P=0.01)$. The homozygous TT genotype was detected in $12.04 \%$ of vitiligo and $9.9 \%$ of control samples, with insignificant difference $(P=0.64)$. The $\mathrm{CT}$ genotype is more common among the healthy controls indicating that the C-819T polymorphism may have a protective effect on the susceptibility to vitiligo $(\mathrm{RR}=0.44, \mathrm{PF}=0.29)$ whereas CC genotype appears to be susceptible to vitiligo $(\mathrm{RR}=1.99, \mathrm{EF}=0.99$, Table 2$)$.

The frequencies of -592 CC genotype was significantly higher in vitiligo patients as compared to controls $(56.62 \%$ vs $39.60 \%, P=0.02)$ while CA genotype was found to be significantly lower $(P=0.01)$ in vitiligo patients $(31.32 \%)$ compared to control subjects (50.49\%). The homozygous AA genotype was detected in $12.04 \%$ of vitiligo and $9.9 \%$ of control samples with no significant difference. The higher frequency of CA genotype among the healthy controls indicated that the individuals with $-592 \mathrm{CA}$ genotype are protected against vitiligo $(\mathrm{RR}=0.44, \mathrm{PF}=0.29)$ while $\mathrm{CC}$ genotype at position -592 of IL-10 seems to be susceptible to vitiligo $(P=0.02, \mathrm{RR}=1.99, \mathrm{EF}=0.99$, Table 3$)$.

\section{Discussion}

IL-10 is a major immunoregulatory cytokine with diverse immunomodulating effects on the immune system. IL-10 is a potent anti-inflammatory Th2 cytokine that down regulates the expression of major histocompatibility complex (MHC) class I and class II molecules, as well as the production of proinflammatory Th1 cytokines [10,18,19,26,50,51,60]. It also has potent stimulatory effects on B lymphocytes resulting in increased production of immunoglobulin and DNA replication [18].

The gene encoding IL-10 has been mapped to chromosome I [29] and the capacity for IL-10 production appears to be genetically encoded. It has been reported that up to $75 \%$ of the variation in IL-10 production is genetically controlled [52]. Moreover, the expression of IL-10 is regulated by different mechanisms in different cell types [34]. The three promoter polymor- 
Table 1

Genotype and allele frequencies of (-1082G/A) IL-10 variants in Vitiligo and matched controls

\begin{tabular}{|c|c|c|c|c|c|c|c|}
\hline \multirow[t]{2}{*}{ Genotype/allele } & \multicolumn{2}{|c|}{ Vitiligo $(N=83)$} & \multicolumn{2}{|c|}{ Control $(N=101)$} & \multirow[t]{2}{*}{$p$-value } & \multirow[t]{2}{*}{$\mathrm{RR}$} & \multirow[t]{2}{*}{$\mathrm{EF} * * / \mathrm{PF}$} \\
\hline & NO. & $\%$ & $\mathrm{NO}$. & $\%$ & & & \\
\hline GG & 15 & 18.07 & 9 & 8.91 & $0.05 *$ & 2.25 & $0.34 * *$ \\
\hline GA & 50 & 60.24 & 74 & 73.26 & $0.04 *$ & 0.55 & 0.24 \\
\hline AA & 18 & 21.68 & 18 & 17.82 & 0.57 & 1.27 & $0.10 * *$ \\
\hline G-allele & 80 & 48.19 & 92 & 45.54 & 0.67 & 1.11 & $0.04 * *$ \\
\hline A-allele & 86 & 51.80 & 110 & 54.45 & 0.67 & 0.89 & 0.05 \\
\hline
\end{tabular}

Table 2

Genotype and allele frequencies of $(819 \mathrm{C} / \mathrm{T})$ IL-10 variants in Vitiligo and matched controls

\begin{tabular}{|c|c|c|c|c|c|c|c|}
\hline \multirow[t]{2}{*}{ Genotype/ allele } & \multicolumn{2}{|c|}{ Vitiligo $(N=83)$} & \multicolumn{2}{|c|}{ Control $(N=101)$} & \multirow[t]{2}{*}{$p$-value } & \multirow[t]{2}{*}{ RR } & \multirow[t]{2}{*}{$\mathrm{EF} * / \mathrm{PF}$} \\
\hline & NO. & $\%$ & NO. & $\%$ & & & \\
\hline $\mathrm{CC}$ & 47 & 56.62 & 40 & 39.60 & 0.02 & 1.99 & $0.99 *$ \\
\hline $\mathrm{CT}$ & 26 & 31.32 & 51 & 50.49 & 0.01 & 0.44 & 0.29 \\
\hline $\mathrm{TT}$ & 10 & 12.04 & 10 & 9.9 & 0.64 & 1.24 & $0.24 *$ \\
\hline C-allele & 120 & 72.28 & 131 & 64.85 & 0.14 & 1.41 & $0.15^{*}$ \\
\hline T-allele & 46 & 27.71 & 71 & 35.14 & 0.14 & 0.70 & 0.13 \\
\hline
\end{tabular}

Table 3

Genotype and allele frequencies of (-592C/A) IL-10 variants in Vitiligo and matched controls

\begin{tabular}{|c|c|c|c|c|c|c|c|}
\hline \multirow[t]{2}{*}{ Genotype/allele } & \multicolumn{2}{|c|}{ Vitiligo $(N=83)$} & \multicolumn{2}{|c|}{ Control $(N=101)$} & \multirow[t]{2}{*}{$p$-value } & \multirow[t]{2}{*}{$\mathrm{RR}$} & \multirow[t]{2}{*}{$\mathrm{EF}^{*} / \mathrm{PF}$} \\
\hline & NO. & $\%$ & NO. & $\%$ & & & \\
\hline $\mathrm{CC}$ & 47 & 56.62 & 40 & 39.60 & 0.02 & 1.99 & $0.99 *$ \\
\hline $\mathrm{CA}$ & 26 & 31.32 & 51 & 50.49 & 0.01 & 0.44 & 0.29 \\
\hline AA & 10 & 12.04 & 10 & 9.9 & 0.64 & 1.24 & $0.24 *$ \\
\hline C-allele & 120 & 72.28 & 131 & 64.85 & 0.14 & 1.41 & $0.15^{*}$ \\
\hline A-allele & 46 & 27.71 & 71 & 35.14 & 0.14 & 0.70 & 0.13 \\
\hline
\end{tabular}

phisms namely $-1082 \mathrm{~A} / \mathrm{G},-819 \mathrm{C} / \mathrm{T}$, and $-592 \mathrm{C} / \mathrm{A}$ lie in putative transcription binding site $[11,12]$, making them important loci to be studied in relation to various disorders and diseases. These polymorphisms exhibit strong linkage disequilibrium and appear in three potential haplotypes (GCC, ACC and ATA) for three loci $(-1082,-819,-592)$ which have been described in various populations $[12,28,41]$. IL-10 production is associated with these haplotypes; it has been suggested that GG genotype is associated with high production, AG genotype is an intermediate producer whereas AA genotype as low producer of IL-10 [12].

In our study, the GG genotype of IL-10 (-1082) was more prevalent in vitiligo patient as compared to healthy control (Table 1) suggesting that the polymorphism at position -1082 could be associated with susceptibility to vitiligo. Our finding is in agreement with earlier genetic studies suggesting that many diseases/conditions like septic shock $[4,21,48]$, acute respiratory syndrome [42], chronic hepatitis C [46], non small cell lung cancer [7], Crohn's disease [36] trauma [53] and mortality in acute renal failure [16] are directly associated with -1082 GG and high circulating IL-10.
In present study intermediate IL-10 producer genotype $-1082 \mathrm{G} / \mathrm{A}$ showed negative association with vitiligo as majority of control subjects have this genotype, suggesting that individuals having $1082 \mathrm{G} / \mathrm{A}$ genotype are less likely to get vitiligo. Interestingly, another study showed that intermediate IL-10 producer genotype -1082 AG exerts protective effect against multiple sclerosis while, high IL-10 producer -1082 GG and low producer 1082-AA genotypes had no association with multiple sclerosis [40].

The frequency of IL-10-819CC was significantly higher in our vitiligo patient as compared to healthy controls, whereas the frequency of IL-10 -819CT, was significantly lower in vitiligo patients. Recently genotype $-819 \mathrm{CC}$ has been reported to be a high producer of IL10 whereas CT and TT as intermediate and low producer [37]. These findings further indicated that genotypes associated with high production of IL-10 are more prevalent in vitiligo patients. The genotypes of Il10-592, being in linkage disequilibrium with the genotypes of Il-10-819 followed the pattern similar to those for frequencies of -819 in vitiligo patients and healthy controls. 
Table 4

Showing sets of sense and antisense primers used to amplify the IL-10 promoter region to detect polymorphism

\begin{tabular}{lcl}
\hline Locus & \multicolumn{1}{c}{ Generic (antisense) primer } & Sense primers \\
\hline IL-10 (-1082) & 5'-CAG TGC CAA CTG AGA ATT TGG-3' & 5'-CTA CTA AGG CTT CTT TGG GAG-3' \\
& & 5'-ACT ACT AAG GCT TCT TTG GGA A-3' \\
IL-10 (-819/-592) & 5'-AGG ATG TGT TCC AGG CTC CT-3' & 5'-CCC TTG TAC AGG TGA TGT AAC-3' \\
& & 5'-ACC CTT GTA CAG GTG ATG TAA T-3' \\
\hline
\end{tabular}

The genotypes of IL-10 (-1082GG, -819CC, $-592 \mathrm{CC}$ ) known to be associated with high production of IL-10 are more prevalent in our vitiligo patients indicating the possible association with susceptibility of vitiligo which is supported by the recent finding that the vitiligo patients show statistically significant increased expression of IL-10, IFN- $\gamma$ and TNF $\alpha$ in involved and adjacent uninvolved skin as compared to controls [45].

It is clear from our results and earlier published reports that some genotypes of IL-10 may enhance the vulnerability of some diseases $[4,7,21,36,42,46,62]$, on the other hand others may exert a protective effect against diseases like breast cancer [62], tuberculosis [22] and leprosy [13]. These findings do not support the inflammatory theory of vitiligo according to which dramatic inflammatory changes including cytotoxic T-lymphocyte (CTL) influx were reported in the lesional margin and in the center of newly formed vitiligo lesions [31]. In fact, inflammatory infiltrates from vitiligonous lesions have been found to contain T-cells specific to melanocytes antigen [6]. IL-10, being a potent anti-inflammatory cytokine produced by Tcells and macrophages strongly inhibits antigen specific T-cell proliferation, cytokine production and $\mathrm{MHC}$ class 2 expression. Thus, our findings are not in agreement with the hypothesis that high IL-10 may dampen the disease process involving inflammatory mechanism. However, some immune stimulating effects of IL-10 have also been documented where it induces activated $\mathrm{B}$ cells to secrete large amounts of $\operatorname{IgG}, \operatorname{IgA}$, and IgM and in combination with IL-4 results in the secretion of four immunoglobulin isotypes. Thus high levels of IL-10 may also play a role in the amplification of humoral responses as suggested by Rousset et al. [18] which may cause melanocyte damage and lead to depigmentation.

In conclusion, our results of IL-10 polymorphism in vitiligo suggested that GG genotype at - 1082 position together with CC genotypes at positions -592 and -819 of IL-10 are susceptible to the development of vitiligo. The three polymorphisms C592A, C819T and G1082A in IL-10 gene promoter region, which were more prevalent in healthy Saudi subjects, might possibly, exert protective effect against vitiligo. This study presents first report of possible association between human IL-10 gene and vitiligo susceptibility and/or heritability in Saudi patients. However, further studies are warranted to investigate IL-10 polymorphism in families with vitiligo.

\section{Materials and methods}

\subsection{Patients and controls}

A total of 184 subjects visiting Armed Forces Hospital, Riyadh, Saudi Arabia were involved in this study. Eighty three Saudi vitiligo patients (40 male, 43 female) and 101 healthy matched voluntary blood donors from same population were recruited. This study was approved by the research and ethics committee of RMH and a written informed consent was obtained prior to recruitment of subjects.

Genomic DNA was extracted from the blood of Vitiligo patients and controls using QIA amp ${ }^{R}$ DNA mini kit (Qiagen CA, USA). Interleukin-10 gene was amplified using amplification refractory mutation systems (ARMS)-PCR methodology [8] to detect any polymorphism involved at various loci viz: -592 . -819 , -1082 . The set of primers used to amplify various types of polymorphism are summarized in Table 4.

\subsection{PCR amplification}

PCR amplification was carried out in Ready to Go PCR Beads (Amersham Biosciences, USA). Reaction consisted of 10 temperature cycles of denaturation for $15 \mathrm{~s}$ at $94^{\circ} \mathrm{C}$, annealing for $50 \mathrm{~s}$ at $65^{\circ} \mathrm{C}$ and extension for $40 \mathrm{~s}$ at $72^{\circ} \mathrm{C}$. Then 25 cycles of denaturation for $20 \mathrm{~s}$ at $94^{\circ} \mathrm{C}$, annealing for $50 \mathrm{~s}$ at $59^{\circ} \mathrm{C}$, extension for $50 \mathrm{~s}$ at $72^{\circ} \mathrm{C}$. Final extension was performed at $72^{\circ} \mathrm{C}$ for $7 \mathrm{~m}$. A positive control was included in the PCR assay by amplification of the human growth hormones (MGH) gene. Electrophoreses of the PCR product was performed in $1.5 \%$ agarose gel, stained with ethidium bromide and photographed. 


\subsection{Statistical analysis}

The differences in genotype and allele frequencies between patients and controls were analyzed by the Fisher's exact test. $P$ values less than 0.05 were considered significant. The strength of the association of disease with respect to a particular genotype/ allele is expressed by odd ratio interpreted as relative risk (RR) following the method of Woolf as out lined by [32]. It is calculated only for those genotypes which are increased or decreased in vitiligo patients as compared to normal Saudis.

Etiologic Fraction (EF): The EF indicates the hypothetical genetic component of the disease. Values $>0.00$ are of significance. It is calculated for positive association (RR $>1)$ [5].

Preventive Fraction (PF): The PF indicates the hypothetical protective effect of one specific antigen for the disease. It is calculated for negative association ( $\mathrm{RR}<$ 1) [5]. Values $<1.0$ indicate the protective effect of the genotype against the manifestation of disease.

\section{Acknowledgements}

The authors would like to thank S. Sadaf Rizvi and Daya Shankar for their help in blood collection and laboratory work.

\section{References}

[1] A. Alkhateeb, P.R. Fain, A. Thody, D.C. Bennett and R.A. Spritz, Epidemiology of vitiligo and associated autoimmune diseases in Caucasian probands and their families, Pigment Cell Res 16 (2003), 208-214.

[2] A. Birol, U. Kisa, G.S. Kurtipek, F. Kara, M. Kocak, E. Erkak et al., Increased tumor necrosis factor alpha (TNF- $\alpha$ ) levels and Interleukin 1 alpha (IL1- $\alpha$ ) levels in the lesional skin of patients with non-segmental vitiligo, I J Dermatol 45 (2006), 992-993.

[3] A.G. Wilson, J.A. Symons, T.L. McDowell, H.O. McDevit and G.W. Duff, Effects of a polymorphism in the human tumor necrosis factor $\alpha$ promoter on transcriptional activation, Proc Nat Acad Sci 94 (1997), 3195-3199.

[4] A. Marchant, J. Deviere, B. Byl, D. De Groote, J.L. Vincent and M. Goldman, Interleukin-10 production during septicemia, Lancet 343 (1994), 707-708.

[5] A. Savejgaard, P. Platz and L.P. Ryder, HLA and disease 1982A survey, Immunol Rev 70 (1983), 193-218.

[6] A. Wankowicz-Kalinska, C. Le Poole, R. van den Wijngaard, W.J. Sorkus and P.K. Das, Melanocyte-Specific immune Response in melanoma and vitiligo: Two faces of the same coin, Pigment Cell Res 16 (2003), 254-260.
[7] C.M. Shih, Y.L. Lee, H.L. Chiou, W.F. Hsu, W.E. Chen, M.C. Chou and L.Y. Lin, The involvement of genetic polymorphism of IL-10 promoter in non-small cell lung cancer, Lung Cancer 50 (2005), 291-297.

[8] C. Perrey, S. Turner, V. Pravica, W.M. Howell and I.V. Hutchinson, ARMS-PCR methodologies to determine IL-10, TNF- $\alpha$, TNF- $\beta$ and TGF- $\beta 1$ gene polymorphisms, Transplant Immunol 7 (1999), 127-128.

[9] C. Seifart, A. Plagens, A. Dempfle, U. Clostermann, C. Vogelmeier, P. von Wichert and U. Seifart, TNF-alpha, TNF-beta, IL-6, and IL-10 polymorphisms in patients with lung cancer, Dis Markers 21 (2005), 157-165.

[10] D.F. Florentino, P. Zlotnik, P. Vieira, T.R. Mosmann, M. Howard, K.W. Moore and A. O'Garra, IL-10 acts on the antigen-presenting cell to inhibit cytokine production by Th1 cells, J Immunol 146 (1991), 3444-3451.

[11] D. Kube, C. Platzer, A. Von Koethen, H. Traub, H. Bohleen, M. Hafner and M. Tesch, Characterization of the promoter activity in Burkitt's lymphoma cell lines, Cytokine 7 (1995), $1-7$.

[12] D.M. Turner, D.M. Williams, D. Sankaran, M. Lazarus, P.J. Sinnott and I.V. Hutchinson, An investigation of polymorphism in the interleukin-10 gene promoter, Eur J Immunogenet 24 (1997), 1-8.

[13] D. Malhotra, K. Darvishi, S. Sood, S. Sharma, C. Grover, V. Relhan, B.S. Reddy and R.N. Bamezai, IL-10 promoter single nucleotide polymorphisms are significantly associated with resistance to leprosy, Hum Genet 118 (2005), 295-300.

[14] E. Crawley, R. Kay, J. Sillibourne, P. Patel, I. Hutchinson and P. Woo, Polymorphic haplotypes of the interleukin-10 5' flanking region determine variable interleukin-10 transcription and are associated with particular phenotypes of juvenile rheumatoid arthritis, Arthritis Rheum 42 (1999), 1101-1108.

[15] E.M. Shajil, S. Chatterjee, D. Agrawal, T. Bagchi and R. Begum, Vitiligo: pathomechanism and genetic polymorphism of susceptible genes, Indian J Exp Biol 44 (2006), 526-539.

[16] E.M. Simmons, J. Himmelfarb, M.T. Sezer, G.M. Chertow, R.L. Mehta, E.P. Paganini, S. Soroko, S. Freedman, K. Becker, D. Spratt et al., Plasma cytokine levels predict mortality in patients with acute renal failure, Kidney Int 65 (2004), 13571365.

[17] E.V. Fowler, R. Eri, G. Hume, S. Johnstone, N. Pandeya, D. Lincoln, D. Templeton and G.L. Radford-Smith, TNF alpha and IL10 SNPs act together to predict disease behavior in Crohn's disease, J Med Genet 42 (2005), 523-528.

[18] F. Rousset, E. Garcia, T. Defrance, N. Vezzio, C. Peronne, D.H. Hsu, R. Kastellein, K.W. Moore and J. Banchereau, Interleukin 10 is a potent growth and differentiation factor for activated human B lymphocytes, Proc Natl Acad Sci USA 89 (1992), 1890-1893.

[19] F.Y. Yue, R. Dummer, R. Geertsen, G. Hofbauer, E. Laine, S. Manolio and G. Burg, Interleukin-10 is a growth factor for human melanoma cells and down-regulates HLA class-I, HLA class-II and ICAM-1 molecules, Int J Cancer 71 (1997), 630-637.

[20] G. He, J.Zhang, X.W. Li, W.Y. Chen, Y.X. Pan, F.P. Yang, N.F. Gu, G.Y. Feng, S.L. Yang, J.Y. He, B.X. Liu, Y.W. Peng, J. Liu and L. He, Interleukin-10-1082 promoter polymorphism is associated with schizophrenia in a Han Chinese sib-pair study, Neurosci Lett 394 (2006), 1-4.

[21] G. Monneret, M.E. Finck, F.Venet, A.L. Debard, J. Bohe, J. Bienvenu and A. Lepape, The anti-inflammatory response dominates after septic shock: association of low moncyte HLA-DR 
expression and high interleukin-10 concentration, Immunol Lett 95 (2004), 193-198.

[22] H.D. Shin, B.L. Park, Y.H. Kim, H.S. Cheong, I.H. Lee and S.K. Park, Common interleukin 10 polymorphism associated with decreased risk of tuberculosis, Exp Mol Med 37 (2005), $128-132$.

[23] I.C. LePoole, P.K. Das, R.M.G.J. van den Wijngaard, J.D. Bos and W. Westerhof, Review of the etiopathomechanism of vitiligo: a convergence theory, Exp Dermatol 2 (1993), 145-153.

[24] I.V. Hutchinson, D. Turner, D. Sankaran, M. Awad, V. Pravica and P. Sinnott, Cytokine genotypes in allograft rejection: guidlines for immunosuppression, Transplant Proc 30 (1998), 3991-3992.

[25] J. Bidwell, L. Keen, G. Gallachar, R. Kimberly, T. Huizinga, M.F. McDermott, J. Oksenberg, J. McNicholl, F. Pociot, C. Hardt and S. D'Alfonso, Cytokine gene polymorphism in human disease: on-line databases, Genes Immun 1 (1999), 3-19.

[26] J.C. Zeller, A. Panoskaltsis-Mortari, W.J. Murphy, F.W. Ruscetti, S. Narula, M.G. Roncarolo and B.R. Blazar, Induction of CD4+ T cell alloantigen-specific hyporesponsiveness by IL-10 and TGF-beta, J Immunol 163 (1999), 3684-3691.

[27] J. Eskdale, D. Kube, H. Tesch and G. Gallagher, Mapping of the human IL10 gene and further characterization of the 5'flanking sequence, Immunogenetics 46 (1997), 120-128.

[28] J. Karjalainen, J. Hulkkonen, M.M.Nieminen, H. Huhtala, A. Aromaa, T. Klaukka and M. Hurme, Interleukin-10 gene promoter region polymorphism is associated with eosinophil count and circulating immunoglobulin $\mathrm{E}$ in adult asthma, Clin Exp Allergy 33 (2003), 78-83.

[29] J.M. Kim, C.I. Brannan, N.G. Copeland, N.A. Jenkins, T.A.K.W. Khan and K.W Moore, Structure of the mouse IL10 gene and chromosomal localization of the mouse and human genes, J Immunol 148 (1992), 3618-3623.

[30] J. Wang, H. Ni, L. Chen, W.Q. Song, Interleukin-10 promoter polymorphism in patients with hepatitis B virus infection or hepatocellular carcinomain Chinese Han ethnic population, Hepatobiliary Pancrat Dis Int 5 (2006), 60-64.

[31] K.E. Sharquie, S.H. Mehenna, A.A. Naji and M. Al-Azzawi, Inflammatory changes in vitiligo: stage II depigmentation, $\mathrm{Am}$ J Dermatopathol 26 (2004), 108-112.

[32] K.U. Schallreuter, C. Levenig, P. Kuhnl, C. Loliger, M. HohlTehari and J. Berger, Histocompatability antigens in vitiligo: Hamburg study on 102 patients from Northern Germany, Dermatology 187 (1993), 186-192.

[33] K.W. Moore, A. O'Garra, R. de Waal Malefyt, P. Vieira and T.R. Mosman, Interleuikin-10, Annu Rev Immunol 11 (1993), 165-190.

[34] K.W. Moore, R. de Waal Malefyt, R.L. Coffman and A. O'Garra, Interleukin-10 and the interleukin-10 receptor, Annu Rev Immunol 19 (2001), 683-765.

[35] K. Zhang, P. Hei, L. Deng and J. Lin, Interleukin-10 gene promoter polymorphisms and their protein production in peritoneal fluid in patients with endometriosis, Mol Hum Reprod 13 (2007), 135-140.

[36] L. Fernandez, A. Martinez, J.L. Mendoza, E. Urcelay, M. Fernandez-Arquero, J. Garcia-Paredes, M. Diaz-Rubio and E.G. de la Concha, Interleukin-10 polymorphisms in Spanish patients with IBD, Inflamm Bowel Dis 11 (2005), 739-743.

[37] M. Addas-Carvalho, T.S.I. Salles and S.T.O. Saad, The association of cytokine gene polymorphism with febrile nonhemolytic transfusion reaction in multitransfused patients, Transfusion Med 19 (2006), 184-191.
[38] M. Arcos-Burgos, E. Parodi, M. Salgar, E. Bedya, J. Buile and D. Jaramillo, Vitiligo: complex segregation and linkage disequilibrium analyses with respect to microsatellite loci spanning the HLA, Hum Genet 110 (2002), 334-342.

[39] M. Howard and A. O'Garra, Biological properties of interleukin 10, Immunol Today 13 (1992), 198-200.

[40] M. Luomala, T. Lehtimaki, H. Huhtala, M. Ukkonen, T. Koivula, M. Hurme and I. Elovaara, Promoter polymorphism of IL10 and severity of multiple sclerosis, Acta Neurol Scand 108 (2003), 396-400.

[41] M. Lyon, C. Lange, S. Lake, E.K. Silverman, A.G. Randolph, D. Kwiatkovaski, B.A. Raby, R. Lazarus, K.M. Weiland. N. Laird and S.T. Weiss, IL-10 gene polymorphisms are associated with asthma in children, Genet Epidemiol 26 (2004), $155-165$.

[42] M.N. Gong, B.T. Thompson, P.L. Williams, W. Zhou, M.Z. Wang, L. Pothier and D.C Christiani, Interleukin-10 polymorphism in position - 1082 and acute respiratory distress syndrome, Eur Respir J 27 (2006), 674-681.

[43] N. Gavalas, S. Akhtar, D. Gawkrodger, P. Watson, A. Weetman and E.H. Kemp, Analysis of allelic variats in the catalase gene in patients with the skin depigmenting disorder vitiligo. Biochem Biophy Res Commun 345 (2006), 1586-1591.

[44] P.D. Katsikis, C.Q. Chu, F.M. Brennan, R.N. Maini, M. Feldmann, Immunoregulatory role of interleukin 10 in rheumatoid arthritis, J Exp Med 179 (1994), 1517-1527.

[45] P.E. Grimes, R. Morris, E. Avaniss-Aghajani, T. Soriano, M. Meraz and A. Metzger, Topical tracolimus therapy for vitiligo: Therapeutic responses and skin messenger RNA expression of proinflammatory cytokines, J Am Acad Dermtol 51 (2004), 52-61.

[46] P.G. Vidigal, J.J. Germer and N.N. Zein, Polymorphism in the interleukin-10, tumor necrosis factor-alpha and transforming growth factor beta1 genes in chronic hepatitis $\mathrm{C}$ patients treated with interferon and ribavirin, I J Heptol 36 (2006), 271-277.

[47] P.P. Majumder, J. J. Nordlund and S.K. Nath, Pattern of familial aggregation of vitiligo, Arch Dermatol 129 (1993), 994 998.

[48] Q. Shu, X. Fang, Q. Chen and F. Stuber, IL-10 polymorphism is associated with increased incidence of severe sepsis, Chin Med J (Engl) 116 (2003), 1756-1759.

[49] R.A. Spritz, K. Gowan, D.C. Bennet and P.R. Fain, Novel vitiligo susceptibility loci on chromosome 7 (AIS2) and (AIS3), confirmation of SLEV1 on chromosome 17, and their roles in an autoimmune diathesis, Am J Hum Genet 74 (2004), 188191.

[50] R. de Waal Malefyt, J. Abrams, B. Bennett, C.G. Figdor and J.E. de Vries, Interleukin 10 (IL-10) inhibits cytokine synthesis by human monocytes: an autoregulatory role of IL-10 produced by monocytes, J Exp Med 174 (1991), 1209-1220.

[51] R. de Waal Malefyt, J. Haanen, H. Spits, M.G. Roncarolo, A. te Velde, C. Figdor, K. Johnson, R. Kastelein, H. Yssel and J.F. de Vries, Interleukin 10 (IL-10) and viral IL-10 strongly reduce antigen-specific human $\mathrm{T}$ cell proliferation by diminishing the antigen-presenting capacity of monocytes via downregulation of class II major histocompatibility complex expression, J Exp Med 174 (1991), 915-924.

[52] R.G. Westendorp, J.A. Langermans, T.W. Huizinga, C.L. Verwiej and A. Sturk, Genetic influences on cytokine production and fatal meningococcal disease, Lancet 349 (1997), 170-173.

[53] R. Neidhardt, M. Keel, U. Steckholzer, A. Safret, U. Ungethuem, O. Trentz and W. Ertel, Relationship of interleukin-10 
plasma levels to severity of injury and clinical outcome in injured patients, J Trauma 42 (1997), 863-870.

[54] S.A. Stanilova, L.D. Miteva, Z.T. Karakolev and C.S. Stefanov, Interleukin-10-1082 promoter polymorphism in association with cytokine production and sepsis susceptibility, Intensive Care Med 32 (2006), 260-266.

[55] S.K. Nath, J.B. Harley and Y.H. Lee, Polymorphisms of complement receptor 1 and interleukin-10 genes and systemic lupus erythematosus: a meta-analysis Hum Genet 118 (2005), 225-234.

[56] S.K. Nath, P.P. Majumder and J.J. Nordlund, Genetic epidemiology of vitiligo: multilocus recessivity cross-validated, Am J Hum Genet 55 (1994), 981-990.

[57] S.L. Ma, N.L Tang, L.C. Lam and H.F. Chiu, The association between promoter polymorphism of the interleukin-10 gene and Alzheimer's disease, Neurobiol Aging 26 (2005), 10051010 .

[58] S. Moretti, A. Spallanzani, L. Amato, G. Hautmann, I. Gallerani, M. Fabiani and P. Fabbri, New insights into the pathogenesis of vitiligo: Imbalance of epidermal cytokines at sites of lesions, Pigment Cell Res 15 (2002), 87-92.
[59] T.R. Mosmann, Properties and functions of interleukin-10, Adv Immunol 56 (1994), 1-10.

[60] T. Tsuruma, A. Yagihashi, T. Torigoe, N. Sato, K. Kijuchi, N. Watanabe and K. Hirata, Interleukin-10 reduces natural killer sensitivity and down regulates MHC class I expression on H-ras-Transformed cells, Cell Immunol 184 (1998), 121-128.

[61] T.W. Huizinga, V. Keijsers, G. Yanni et al., Are differences in interleukin 10 production associated with joint damage? Rheumatology 39 (2000), 1180-1188.

[62] U. Langsenlehner, P. Krippl, W. Renner, B. Yazdani-Biuki, T. Eder, H. Koppel, T.C. Wascher, B. Paulweber and H. Samonigg, Interleukin-10 promoter polymorphism is associated with decreased breast cancer risk, Breast Cancer Res $\mathbf{9 0}$ (2005), 113-115.

[63] Y. Honda, Y. Okubo and M. Koga, Relationship between levels of soluble interleukin-2 receptors and the types of activity of vitiligo, J Dermatol 24 (1997), 561-563.

[64] Y.H. Chang, C.N. Huang, C.Y. Wu and M.Y. Shiau, Association of interleukin-10 A-592C and T-819C polymorphisms with type 2 diabetes mellitus, Hum Immunol 66 (2005), 12581263. 


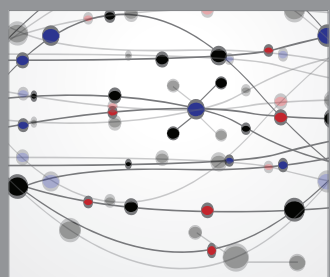

The Scientific World Journal
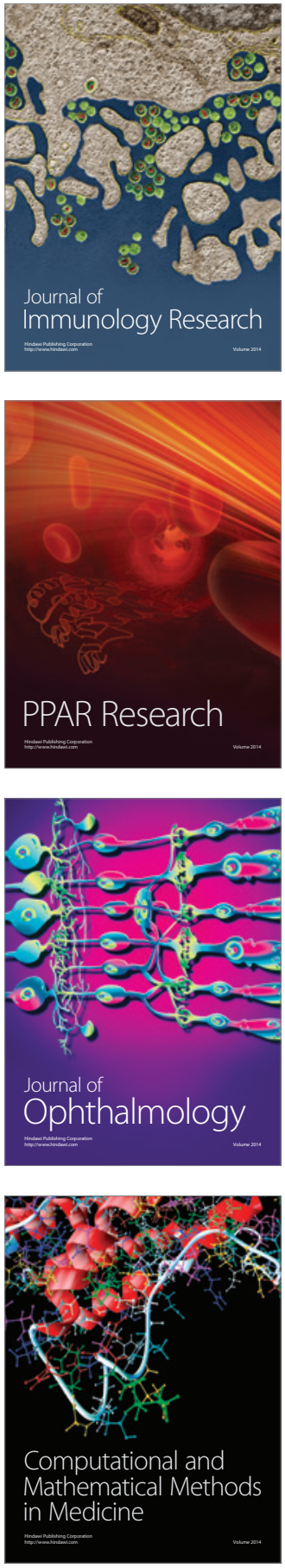

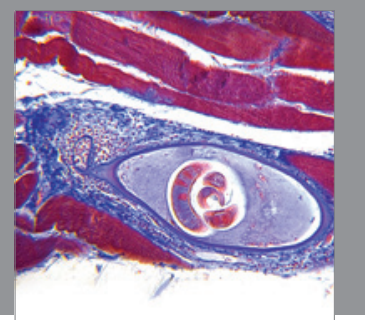

Gastroenterology

Research and Practice
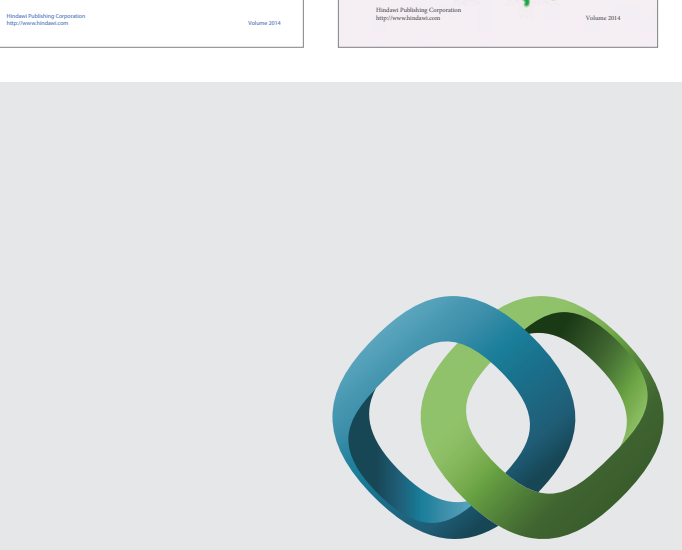

\section{Hindawi}

Submit your manuscripts at

http://www.hindawi.com
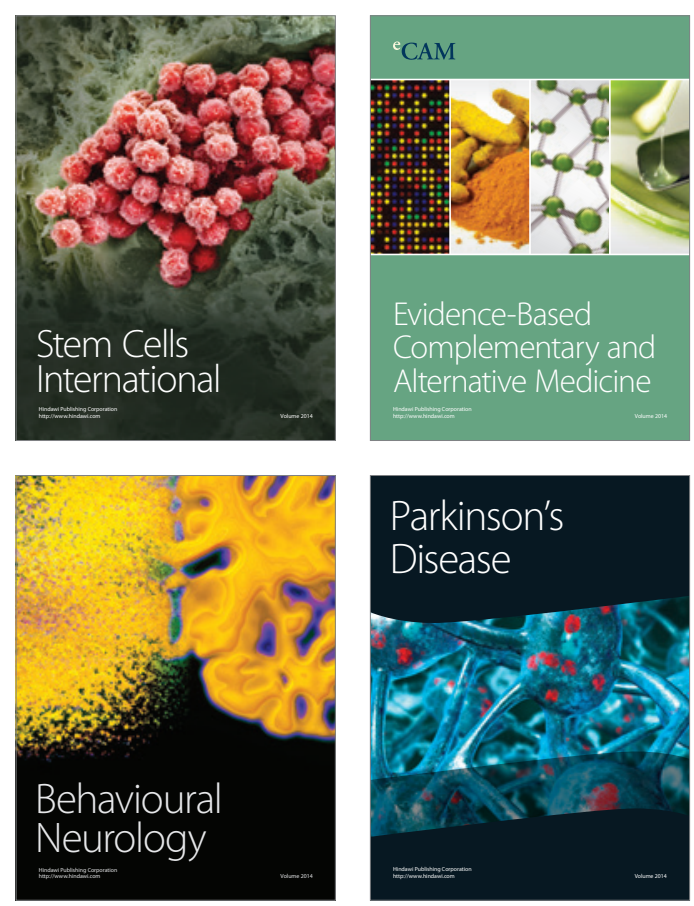

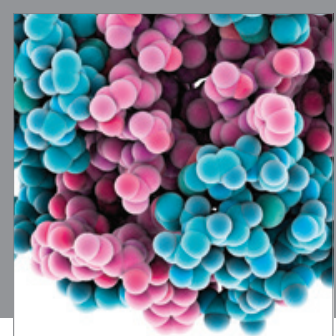

Journal of
Diabetes Research

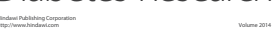

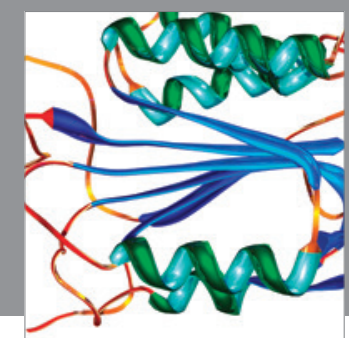

Disease Markers
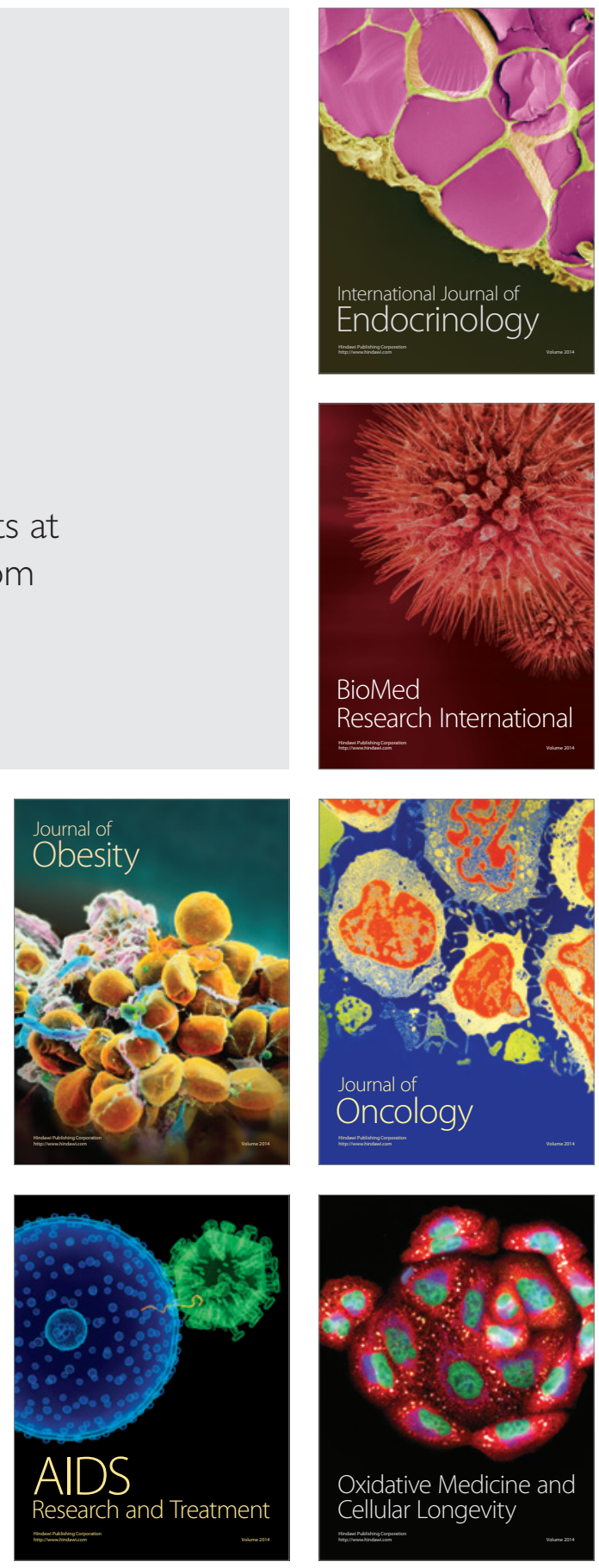